\title{
Corrigendum to: Why is the relative abundance of Asterionella formosa increasing in a Boreal Shield lake as nutrient levels decline?
}

\author{
Branaavan Sivarajah • Kathleen M. Rühland - Andrew L. Labaj • \\ Andrew M. Paterson · John P. Smol
}

Published online: 17 May 2016

(C) Springer Science+Business Media Dordrecht 2016

\section{Corrigendum to: J Paleolimnol (2016) 55:357-367 DOI 10.1007/s10933-016-9886-2}

Upon reading the published version of Sivarajah et al. (2016), we noted the last two sentences in the Results (p. 361, right-hand column) should read:

The increase in the relative abundance of A. formosa shows no relationship to the decline in
TIN (Spearman Rank correlation: $r_{\mathrm{s}}=-0.26$, $\mathrm{N}=14, p=0.37$ ) and is marginally related (but not statistically significant at alpha $=0.05)$ to the increase in mean annual air temperature (Spearman Rank correlation: $r_{\mathrm{s}}=0.40, \mathrm{~N}=19, p=0.09$ ).

B. Sivarajah · K. M. Rühland · A. L. Labaj ·

J. P. Smol ( $\varangle)$

Paleoecological Environmental Assessment and Research Laboratory, Department of Biology, Queen's University,

Kingston, ON, Canada

e-mail: smolj@queensu.ca

\section{A. M. Paterson}

Dorset Environmental Science Centre, Ontario Ministry

of the Environment and Climate Change, Dorset, ON,

Canada 